\title{
Subversion of Cell Signaling by Pathogens
}

\section{Neal M. Alto and Kim Orth}

UT Southwestern Medical Center, Dallas, Texas 75390

Correspondence: kim.orth@utsouthwestern.edu

\section{SUMMARY}

Pathogens exploit several eukaryotic signaling pathways during an infection. They have evolved specific effectors and toxins to hijack host cell machinery for their own benefit. Signaling molecules are preferentially targeted by pathogens because they globally regulate many cellular processes. Both viruses and bacteria manipulate and control pathways that regulate host cell survival and shape, including MAPK signaling, G-protein signaling, signals controlling cytoskeletal dynamics, and innate immune responses.

\section{Outline}

1 Introduction

2 Corruption of MAPK signaling

3 Manipulation of G-protein signaling

4 Highjacking lipid signaling
5 Other actin regulators targeted by pathogens

6 Targeting ubiquitin-mediated signal transduction

7 Conclusion

References

Editors: Lewis Cantley, Tony Hunter, Richard Sever, and Jeremy Thorner

Additional Perspectives on Signal Transduction available at www.cshperspectives.org

Copyright $\odot 2012$ Cold Spring Harbor Laboratory Press; all rights reserved; doi: 10.1101/cshperspect.a006114 


\section{INTRODUCTION}

Viruses and bacteria both produce proteins that hijack cellular signaling machinery to ensure their survival despite the constant negative pressure of their hosts' innate and adaptive immune systems. Studies of these have not only revealed methods by which microbial pathogens cause infectious disease, but also provided critical insights into mechanisms of cellular regulation, particularly in the case of viral oncoproteins (see Box 1). They also yielded valuable tools for dissecting mechanisms involved in regulating signaling.

These proteins help a pathogen achieve its goals of survival, replication, and virulence. For example, they may induce a slow cell death to allow time for replication or cause a rapid cell death so that the pathogen avoids engulfment. Alternatively, they may manipulate the actin cytoskeleton to prevent or accelerate phagocytosis by the host. In the case of viral oncoproteins, they may hijack the cell cycle machinery to promote virus replication.

Here, we do not attempt to be comprehensive, but provide representative examples of how pathogens manipulate host cell signaling, emphasizing the virulence factors produced by bacterial pathogens (Table 1). Targets for these virulence factors include GTPases and their regulators that control the cytoskeleton and vesicular trafficking, kinase cascades involved in intra- and extracellular signaling, and ubiquitin-dependent pathways that regulate signal stability or dictate other outputs.

Bacteria produce different types of virulence factors. Note that these are not always proteins-they may also be peptides or small molecules - but here we confine our discussion to proteins. The first type, called a toxin, is secreted by the pathogen at high concentration and delivered into the host cytoplasm by a variety of mechanisms, including endocytosis or via protein pores formed by the bacterial toxin itself (Fig. 1) (Henkel et al. 2010). Cholera toxin from Vibrio cholerae, for example, is an enzyme that enters the cell by endocytosis and ADP-ribosylates the $\alpha_{s}$ subunit of the heterotrimeric $G_{s}$ protein. This modification prevents $\alpha_{s}$ from hydrolyzing GTP, locking it into an active state that constitutively stimulates its downstream effector, adenylyl cyclase (see Sassone-Corsi 2012). In the intestinal epithelium, the elevated levels of cyclic AMP (cAMP) generated cause an efflux of chloride ions and water, resulting in severe diarrhea and dehydration. Pertussis toxin produced by Bordetella pertussis, which causes whooping cough, by contrast, ADP ribosylates the $\alpha_{\mathrm{i}}$ subunit of the heterotrimeric $G_{i}$ protein so that it remains in the GDP-bound state and cannot be activated by upstream signals. The modified

\section{BOX 1. VIRAL ONCOPROTEINS}

Studies of viruses have provided critical biological insights into the signal transduction mechanisms of host cells. More than a century ago, Peyton Rous described Rous Sarcoma Virus (RSV) as a transforming agent that induces solid tumors in chickens. Although this discovery was met with some skepticism at the time, researchers in the 1970s and 1980s isolated and sequenced the viral non-receptor tyrosine kinase-encoding $v$-src gene as the genetic element that causes tumor formation. In fact, $v$-src was the first retroviral oncogene discovered, and this discovery helped define the first proto-oncogene in the vertebrate genome ( $c$-Src, now known simply as $\mathrm{Src}$ ). Further investigations into oncoviruses also revealed $\mathrm{v}$-Abl, the retroviral oncoprotein from the Abelson murine leukemia virus (A-MuLV). Like $v$-src, $v$-Abl encodes a nonreceptor tyrosine kinase that is genetically and functionally related to the $A B L$ gene in mammals. In humans, the translocation involving chromosomes 22 and 9 (known as the Philadelphia chromosome) causes the first exon in $A B L 1$ to be replaced by sequences from the $B C R$ gene, resulting in expression of the BCR$\mathrm{ABL}$ fusion protein. This genetic translocation results in abnormally high levels of $\mathrm{BCR}-\mathrm{ABL}$ kinase activity, leading to chronic myeloid leukemia (CML) and a subset of acute lymphocytic leukemia (ALL). Biochemical and structural studies led to one of the successful medicinal treatments for cancer: a specific, small molecule kinase inhibitor referred to as imatinib or GLEEVAC.

Studies of the transforming activity of murine sarcoma viruses were also particularly influential in stimulating work that elucidated small G-protein signaling in human cancer. In the 1960s, the first Ras (for Rat sarcoma) genes were identified as transduced oncogenes expressed by the Harvey and Kirsten strains of acutely transforming murine retroviruses. More than a decade later, researchers discovered that these viral Ras proteins interface with guanine nucleotide signaling mechanisms through an intrinsic GTPase activity. Several human genes were subsequently found to display sequence homology to viral Ras. The identification of $R A S$ as the first human transforming gene set off a global research initiative aimed at discovering the molecular mechanisms of small G proteins.

Interestingly, the major downstream substrate of Ras signal transduction is Raf kinase, encoded by the cellular homolog of the $v$ raf oncogene expressed by the murine retrovirus 3611-MSV. Under normal conditions, binding of extracellular ligands such as growth factors, cytokines, and hormones to cell-surface receptors activates Ras, and this initiates Raf activation. Indeed, both lie downstream from the EGF receptor, which also has a viral oncogene homolog, $v$-erbB. Thus, not only has research on viral oncogenes been an entry point into the molecular genetics of cancer, but it has also revealed critical links between infectious disease mechanisms and eukaryotic signal transduction. 
Table 1. Bacterial toxins and effectors and their targets

\begin{tabular}{|c|c|c|c|c|}
\hline Pathogen & Toxin & Effector & Target & Activity \\
\hline Vibrio cholerae & Cholera toxin & & $\mathrm{G} \alpha_{\mathrm{s}}$ & ADP ribosylation \\
\hline Vibrio cholerae & EF edema factor & & Calmodulin & Adenylate cyclase \\
\hline Vibrio cholerae & LF lethal factor & & MKK1,2 & Metalloprotease \\
\hline Bordetella pertussis & Pertussus toxin & & $\mathrm{G} \alpha_{\mathrm{i}}$ & ADP ribosylation \\
\hline Clostridium botulinum & C3 botulin toxin & & Rho GTPases & ADP ribosylation \\
\hline Escherichia coli & CNF1 & & Rho GTPases & Deamination \\
\hline EPEC/EHEC O157:H7 & & Tir & Actin & Recruits NCK adaptor \\
\hline EPEC/EHEC O157:H7 & & Map & Rho GTPases & GEF \\
\hline EPEC/EHEC O157:H7 & & EspFu & N-WASP & Activator of N-WASP \\
\hline EPEC/EHEC O157:H7 & & EspG & p21-activated kinase (PAK) & Activator of PAK \\
\hline EPEC/Burkholderia spp. & & Cif/CBHP & Ubiquitin, Nedd8 & Ubiquitylation inhibitor \\
\hline Yersinia spp. & & YopH & p130Cas & Tyrosine phosphatase \\
\hline Yersinia spp. & & YopE & Rho-like GTPases & GAP \\
\hline Yersinia spp. & & YopT & Rho GTPase & Cysteine protease \\
\hline Yersinia spp. & & YpkA & G $\alpha_{\mathrm{q}}$, Rho GTPases & Ser/Thr kinase, GDI \\
\hline Yersinia spp. & & YopJ & MAPKKs, IKK- $\beta$ & Ser/Thr acetyltransferase \\
\hline Vibrio parahaemolyticus & & VopA/p & MAPKKs & Ser/Thr/Lys acetyltransferase \\
\hline Vibrio parahaemolyticus & & VopS & Rho-GTPases & AMPylation \\
\hline Vibrio parahaemolyticus & & VPA0450 & Phosphatidylinositol 4,5-bisphosphate & Lipid phosphatase \\
\hline Vibrio parahaemolyticus & & VopL & Actin & Actin nucleator \\
\hline Histophilus somni & & IbpA & Rho GTPases & Ampylation \\
\hline Legionella pneumophila & & DrrA/SidM & Rablb & AMPylation, GEF \\
\hline Legionella pneumophila & & SidD & Rablb & DeAMPylation \\
\hline Legionella pneumophila & & AnkX & Rablb & Phosphocholination \\
\hline Shigella spp. & & OspF & MAPK & Phosphothreonine lyase \\
\hline Shigella spp. & & IpgD & Phosphatidylinositol 4,5-bisphophate & Lipid phosphatase \\
\hline Shigella spp. & & IpaH9.8 & Ste7 MAPK & E3 ubiquitin ligase \\
\hline Shigella spp. & & IpgB2 & Racl and RhoA & GEF \\
\hline Salmonella spp. & & SopB & Phosphatidylinositol 4,5-bisphophate & Lipid phosphatase \\
\hline Salmonella spp. & & SopE & Cdc42 and Rac GTPases & GEF \\
\hline Salmonella spp. & & SptP & Small GTPase & GAP, tyrosine phosphatase \\
\hline Pseudomonas aeruginosa & & ExoS & Small GTPases & ADP ribosylation, GAP \\
\hline Listeria monocytogenes & & ActA & $\operatorname{Arp} 2 / 3$, actin & Activator of Arp2/3 \\
\hline \multicolumn{5}{|l|}{ Viral effector } \\
\hline Vaccinia virus & & $\mathrm{A} 36 \mathrm{R}$ & Actin & Adaptor recruits Nck and Grb2 \\
\hline Adenovirus & & E1B-55K & p53, Mre11, BLM helicase & Ubiquitin ligase adaptor \\
\hline Adenovirus & & E4orf6 & p53, Mre11, BLM helicase & Ubiquitin ligase adaptor \\
\hline Papillomavirus & & E6 & E6-AP, p53 & E3 ubiquitin ligase \\
\hline KSHV & & RTA & IRF-7 & E3 ubiquitin ligase \\
\hline Gammaherpesviruses & & $\mathrm{K} 3$ and $\mathrm{K} 5$ & MHC class 1 & E3 ubiquitin ligase \\
\hline Herpes simplex virus 1 & & ICP0 & PML & E3 ubiquitin ligase \\
\hline
\end{tabular}

GDP-bound $\alpha_{\mathrm{i}}$ is no longer able to bind to adenylyl cyclase and inhibit production of cAMP. Pertussis toxin causes major trauma in airways during infection because signaling pathways are constitutively activated and results in abnormally high levels of insulin and histamine sensitivity. These toxins have proven very useful for the elucidation of molecular signaling by G-protein-coupled receptors (GPCRs) and their downstream signaling partners.

Another type of virulence factor, called an effector, is a protein that is directly translocated from bacteria into the host cell by specialized needle-like delivery systems, including the type III and type IV secretion systems (T3SS and T4SS, respectively) (Fig. 1) (Hayes et al. 2010). The effectors are made in the bacterium but appear to be inactive because of association with a chaperone, lack of appropriate substrate, and/or absence of eukaryotic activators. After delivery into the eukaryotic host, the effectors display very potent activities that manipulate signal transduction pathways. Many of these activities mimic an endogenous activity of the host.

The first such effector analyzed at the molecular level was YopH (Yersinia outer protein H) from Yersinia, the causal 


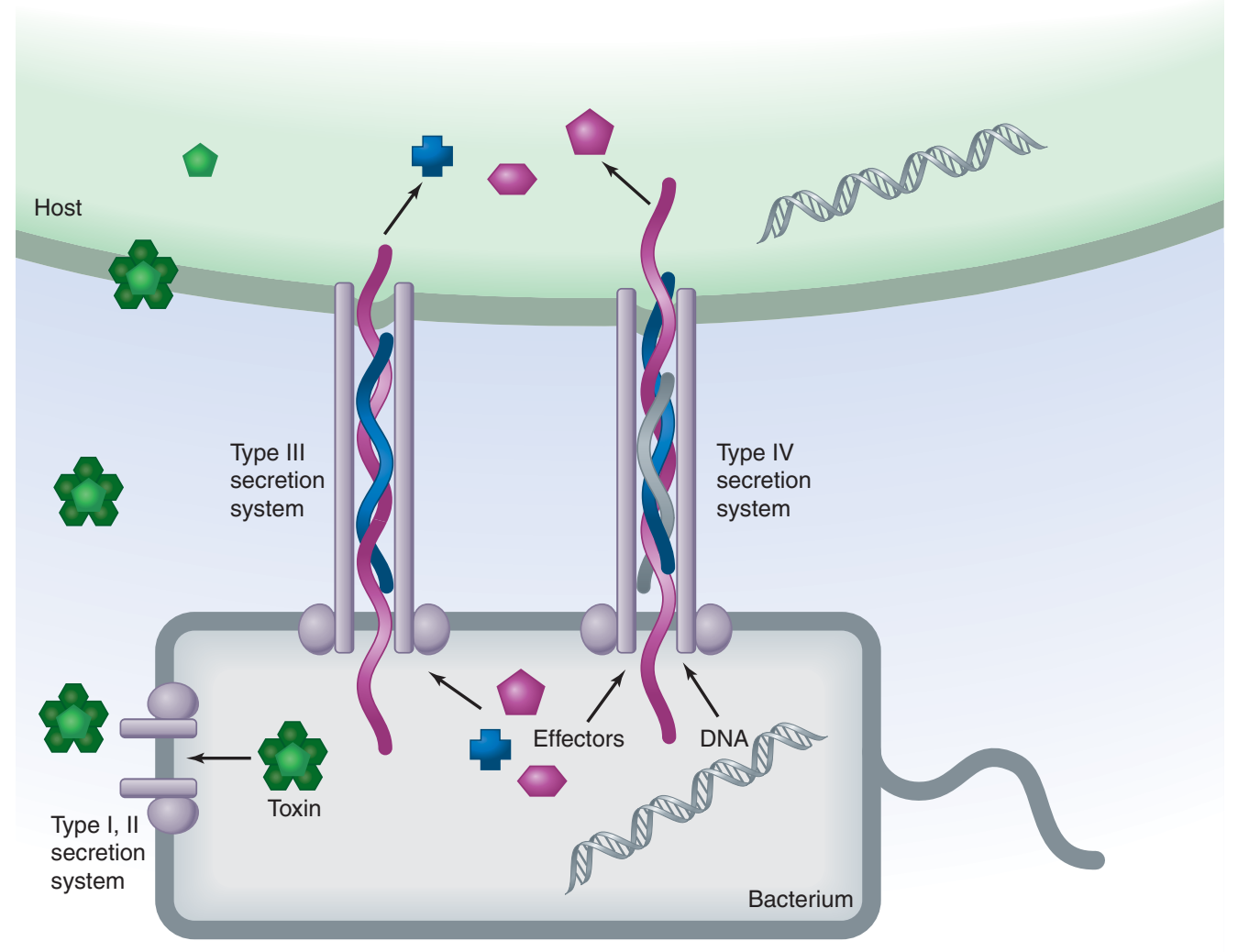

\begin{abstract}
Figure 1. Bacterial secretion systems. Bacteria use several different mechanisms to secrete molecules into the extracellular space and to translocate molecules into a host cell. Toxins, including peptides and proteins, are typically secreted through a type I or II secretion system. Effectors are translocated through a type III or IV secretion system, whereas DNA is only transferred through the type IV secretion system.
\end{abstract}

agent of the Plague (also known as the Black Death) (Guan and Dixon 1990). This protein contains an unregulated, highly active tyrosine phosphatase domain linked to a leader sequence that both guides its translocation from the bacterium into the host cell and determines its localization after delivery. YopH is translocated into eukaryotic cells through the Yersinia T3SS and proceeds to focal adhesions, where it dephosphorylates critical phosphorylated tyrosine residues on protein substrates including p130Cas and Fyb (see Devreotes and Horwitz 2012). The resulting dephosphorylated focal adhesion complex disassembles and, therefore, is unable to promote phagocytosis of the bacterial pathogen. YopH is a typical bacterial effector for the following reasons.

1. Although an extremely active enzyme, YopH has no effect on the pathogen itself, owing to the lack of a substrate.

2. The YopH protein contains information in its aminoterminal domain for both secretion by the T3SS apparatus and localization in the infected host.
3. YopH contains a potent activity that efficiently targets and destroys the Achilles heel of a process, in this case, phagocytosis, by targeting focal adhesions that are regulated by phosphorylated tyrosine residues.

4. YopH plays a critical role in virulence.

Below, we describe several other pathogenic effectors that show these general characteristics, breaking them down by the signaling pathways they target.

\section{CORRUPTION OF MAPK SIGNALING}

Mitogen-activated protein kinase (MAPK) signaling pathways are cascades of kinases that sequentially activate each other by phosphorylation (Morrison 2012). A MAPK kinase kinase (MAPKKK) activates a MAPK kinase (MAPKK), which, in turn, activates a MAPK, and there are multiple family members at each stage. Pathogens target these signaling pathways because they regulate many types of cellular behaviors, including cell proliferation, innate immune responses, cell migration, apoptosis, and autophagy. 


\subsection{Bacillus anthracis Lethal Factor Hydrolyzes the MAPKK MKK1/2}

Bacillus anthracis, the causal agent of Anthrax, releases a multi-subunit complex called anthrax toxin, composed of protective antigen (PA), edema factor (EF), and lethal factor (LF) (Collier 2009). The toxin binds via PA to either anthrax toxin receptor 1 or 2 on the surface of the host cell. After uptake by receptor-mediated endocytosis and acidification of the resulting endosome, EF and LF are released into the cytoplasm. The calcium-binding protein calmodulin binds to cytoplasmic EF, causing a change in conformation that generates an active enzyme that produces cAMP from cellular ATP. The excess cAMP globally disrupts signaling by binding and activating downstream effectors, such as cAMP-dependent kinase (PKA). Cytoplasmic LF is an active metalloprotease that cleaves the amino-terminal extensions from MAPKKs MKK1 and MKK2, producing kinases that can no longer interact with their substrates to activate a proliferative response (Fig. 2). Both of the toxins have an irreversible toxic effect on the infected cell.

\subsection{Yersinia YopJ Acetylates MAPKK/IKK $\beta$ Activation Loop}

Yersinia ssp. have a very efficient strategy for disrupting the innate immune response and promoting apoptosis in infected cells, using one molecule, YopJ (also termed YopP). This effector is injected directly into the host's cytoplasm through a T3SS. YopJ blocks all of the MAPK pathways and the NF- $\kappa \mathrm{B}$ pathway by preventing the activation of all MAPKKs and IKK $\beta$ (but not IKK $\alpha$ ) (Fig. 2) (Orth et al. 1999; Hao et al. 2008; Morrison 2012; Staudt 2012). The activity of this 32-kDa effector remained elusive for many years because it contains a catalytic triad similar to that in some cysteine proteases, specifically clan CE proteases, which include adenoviral proteases and ubiquitin-like protein proteases (Orth et al. 2000). However, a classical biochemical approach finally revealed that YopJ does not cleave MAPKKs or any other substrate; instead, it modifies MAPKKs with a small acetyl moiety. This acetyltransferase activity requires an intact catalytic triad and uses acetylCoA to modify serine and/or threonine residues in the activation loops of MAPKKs and IKK $\beta$, generating a novel posttranslational modification that competes with phosphorylation (Mittal et al. 2006; Mukherjee et al. 2006).

These findings revealed a new paradigm for signaling, in which serine and threonine residues could be substrates for acetylation (Mukherjee et al. 2007). So how is the catalytic triad of a presumed protease used for acetylation? In fact, YopJ acetyltransferases and clan CE cysteine proteases are both proposed to use the same catalytic "ping-pong" mechanism (Fig. 3). Acetyltransferases containing a catalytic triad react with acetyl-CoA to form a covalent acetylenzyme intermediate and release CoA. They then bind their substrate and transfer the acetyl group to the substrate's attacking nucleophile. Cysteine proteases use the

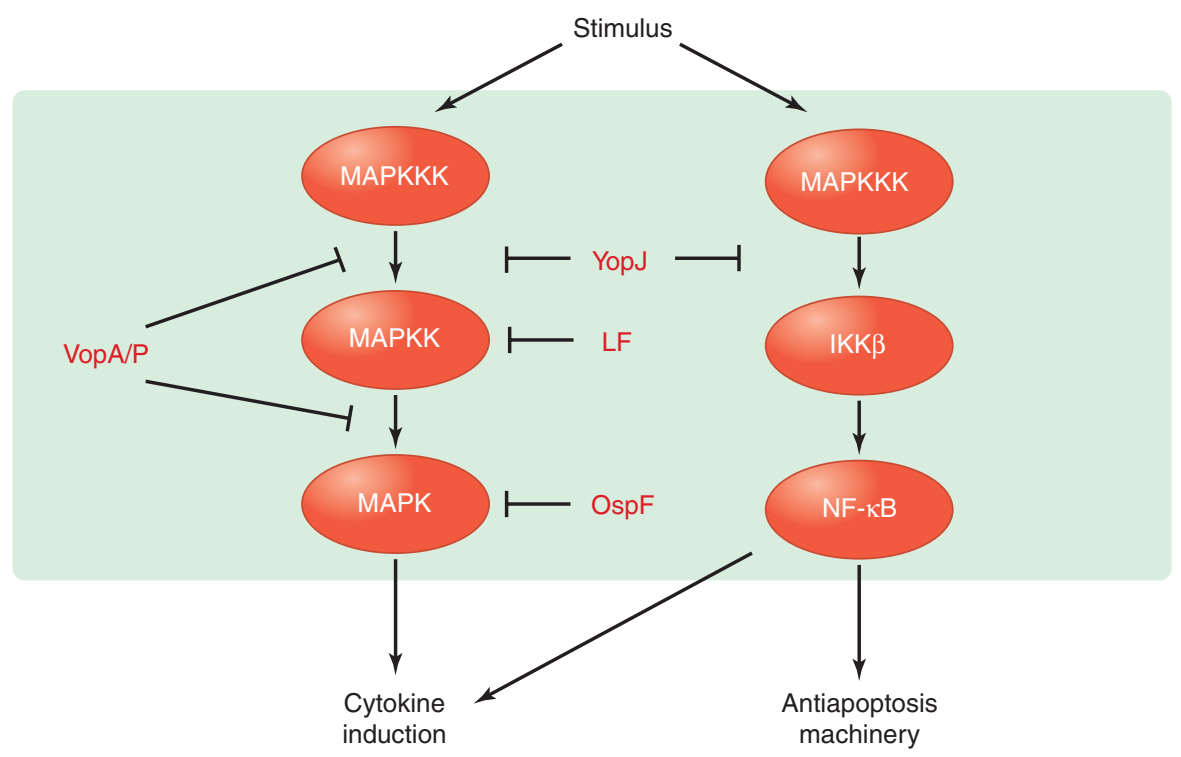

Figure 2. Corruption of MAPK and NFKB signaling pathways by bacterial effectors. Yersinia YopJ is an acetyltransferase that acetylates and inhibits MAPKK and IKK $\beta$ activation by blocking phosphorylation. Similarly, Vibrio VopA/P blocks activation of MAPKK. Lethal factor (LF) from B. anthracis, the causal agent of Anthrax, is a metalloprotease that inhibits MAPKK by proteolysis. OspF is a phosphothreonine lyase that irreversibly dephosphorylates MAPK by elimination of a phosphate group from activated MAPK. 


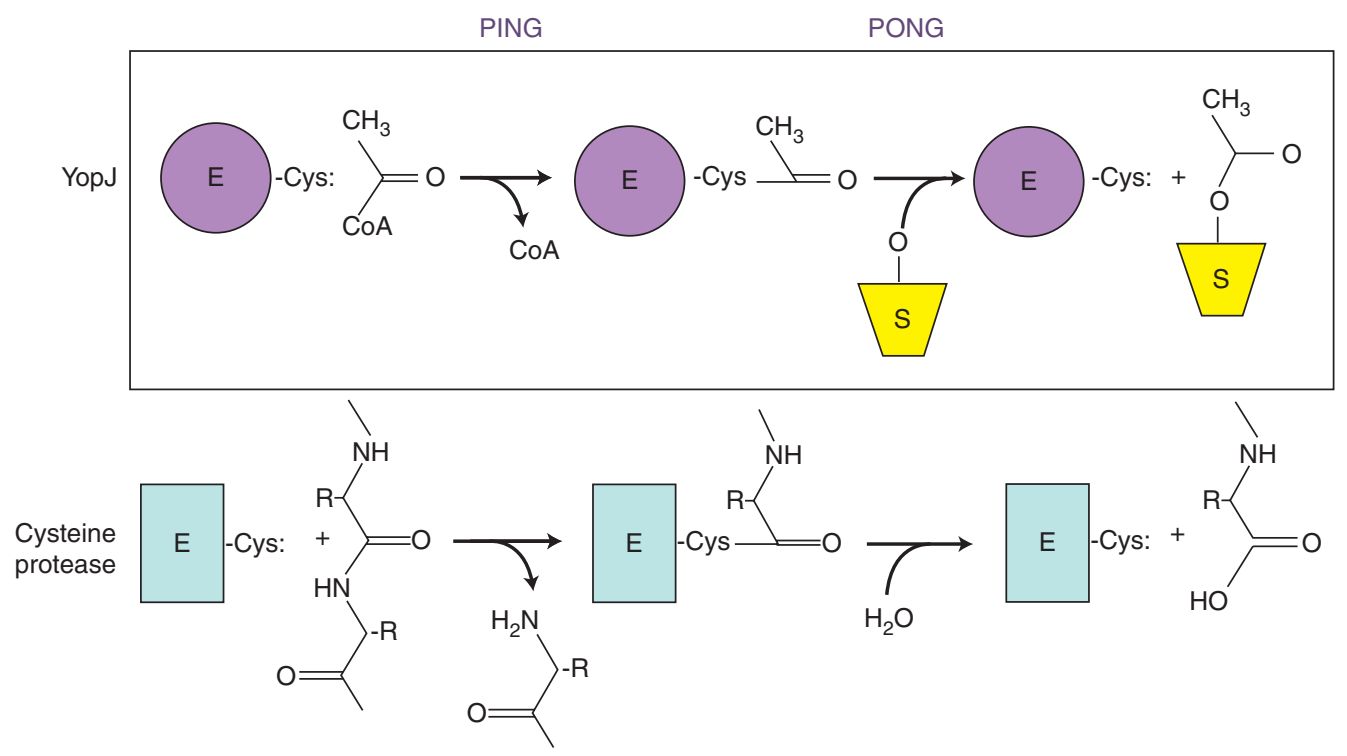

Figure 3. Catalytic triads: same chemistry, different substrates. Yersinia YopJ is proposed to use a ping-pong mechanism whereby its catalytic cysteine attacks acetyl-CoA to form a covalent acetyl-enzyme intermediate, followed by a subsequent attack by its second substrate, a hydroxyl on MAPKK, to transfer the acetyl group to MAPKK. A cysteine protease uses the same mechanism with a peptide to form a covalent acetyl-enzyme intermediate. The second substrate in this reaction is water and leads to cleavage of a peptide bond.

same mechanism to form a covalent acyl-enzyme intermediate, release the carboxy-terminal peptide, and then use a second substrate, water, to attack the acyl-enzyme covalent intermediate to complete the hydrolase reaction. Acetyl transferases do not allow water in the catalytic site; otherwise, these enzymes would simply hydrolyze the essential metabolite acetyl-CoA.

During an infection, signals for host survival and apoptosis are induced. In the presence of YopJ, the default pathway will always be death because YopJ blocks the NF$\mathrm{\kappa B}$ survival pathway. By inhibiting signaling pathways that alert the immune system and induce survival signals, YopJ attenuates the immune response to Yersinia during infection. In contrast, VopA/P, a YopJ relative from the seafoodborne pathogen Vibrio parahaemolyticus that causes food poisoning, inhibits MAPK signaling pathways but not the NF-кB pathway (Fig. 2) (Trosky et al. 2004). Additionally, VopA/P acetylates not only the activation loop of MAPKKs but also a conserved lysine residue in the catalytic loop of MAPKKs that is required for coordination of the $\gamma$-phosphate of ATP (Trosky et al. 2007). This inhibits the binding of ATP but not ADP, resulting in an inactive kinase. During infection by $V$. parahaemolyticus, VopA/P efficiently blocks proliferative pathways while allowing activation of survival pathways. Our understanding of this infectious process is in its infancy; thus the activities of the other secreted effectors will need to be uncovered to shed light on the importance of VopA/P inhibition. Note that this type of serine/threonine acetylation has not yet been observed as an endogenous protein modification in eukaryotes.

\subsection{Shigella OspF Irreversibly Eliminates a Phosphate}

Shigella, the causal agent of bloody dysentery, contains the T3SS effector OspF, which is a phosphothreonine lyase that translocates to the host nucleus upon infection. This enzyme eliminates a phosphate group from a phosphothreonine residue in the activation loop of the MAPKs ERK1 and ERK2 by $\beta$-elimination of the hydroxyl moiety, an unprecedented reaction mechanism for removing a phosphate from a protein, which generates dehydroalanine (Fig. 2) (Li et al. 2007). This irreversible dephosphorylation inhibits ERK-mediated activation of downstream mitogen- and stress-activated kinase 1 (MSK1) and MSK2, thereby preventing phosphorylation of histone $\mathrm{H} 3$ on S10. This modification is a prerequisite for chromatin reorganization and priming of transcription-factor-binding sites in NF-кBregulated promoters (Newton and Dixit 2012). Initial studies supported the hypothesis that OspF works to diminish a proinflammatory response during a Shigella infection, but other studies implicate an OspF-mediated inhibition of a negative-feedback loop to partially activate immune signaling, which may create an advantageous environment for this intracellular pathogen. 


\section{MANIPULATION OF G-PROTEIN SIGNALING}

Among the Ras superfamily of small G proteins, the Ras, Rho, and Ran subfamilies primarily regulate cell division/ differentiation, cytoskeleton remodeling, and nuclear import, respectively (Takai et al. 2001; Yaffe 2012). Members of the Arf and Rab subfamilies facilitate many aspects of intracellular trafficking (Takai et al. 2001). As in the case of heterotrimeric $\mathrm{G}$ proteins, nucleotide binding regulates small G proteins: GTP-bound small G proteins are in an active conformation, and GDP-bound small G proteins are in an inactive conformation. Unsurprisingly, they are important targets of viral and bacterial virulence factors, as are the guanine-nucleotide exchange factors (GEFs) and GTPase-activating proteins (GAPs) that regulate them (Yaffe 2012). Indeed, the diverse regulatory processes they control make them prime targets, allowing pathogens to subvert host machinery in order to mediate cellular attachment and entry and promote growth, replication, and dissemination of the pathogen within the harsh environment of the host. There is an impressive list of secreted virulence factors that mimic or modify the behavior of host small G proteins (Table 1).

\subsection{Bacterial Guanine-Nucleotide Exchange Factor (GEF) Mimics}

The pathogenic strategy underlying the subversion of small $\mathrm{G}$ proteins during infection depends on the bacterial life cycle. For example, Salmonella, the causal agent of typhoid fever, is intracellular and deploys bacterial GEF proteins such as SopE and SopE2 to activate actin polymerization, which facilitates internalization of the bacterium into host cells. SopE directly activates the Cdc42 and Rac small $\mathrm{G}$ proteins to induce membrane ruffling at the site of Salmonella invasion (Fig. 4) (Hardt et al. 1998). SopE2 (Salmonella spp.), BopE (Burkholderia pseudomallei), and CopE (Chromobacterium violaceum) are similar to SopE. A second class of bacterial GEFs shares very low sequence similarity $(<15 \%)$ with one another, but all contain an invariant WxxxE motif (Alto et al. 2006; Huang et al 2009). This extends the group of pathogens that directly activate host small $\mathrm{G}$ proteins to the facultative intracellular pathogens Shigella spp. and the extracellular Attaching/ Effacing (A/E) Escherichia coli pathogens, including entrohemorrhagic E. coli O157:H7 (EHEC O157:H7) and enteropathogenic E. coli (EPEC).

Bioinformatics analyses reveal that SopE-type and WxxxE-type bacterial GEFs share no overall sequence similarity, yet both classes adopt a conserved V-shape structure and promote the exchange of guanine nucleotides by presenting conserved acidic and amide residues necessary for stabilization of switch I and switch II regions on the target small G proteins (Buchwald et al. 2002; Upadhyay et al. 2008; Huang et al. 2009). However, unlike many forms of pathogenic mimicry, the bacterial GEFs are functional mimics that have structures completely different from those of their eukaryotic counterparts. Indeed, they resemble neither the eukaryotic Dbl-homology (DH) domain nor the dock homology region 2 (DHR2) domain proteins, the two major classes of eukaryotic Rho-family GEFs. Nevertheless, both bacterial and eukaryotic GEFs induce

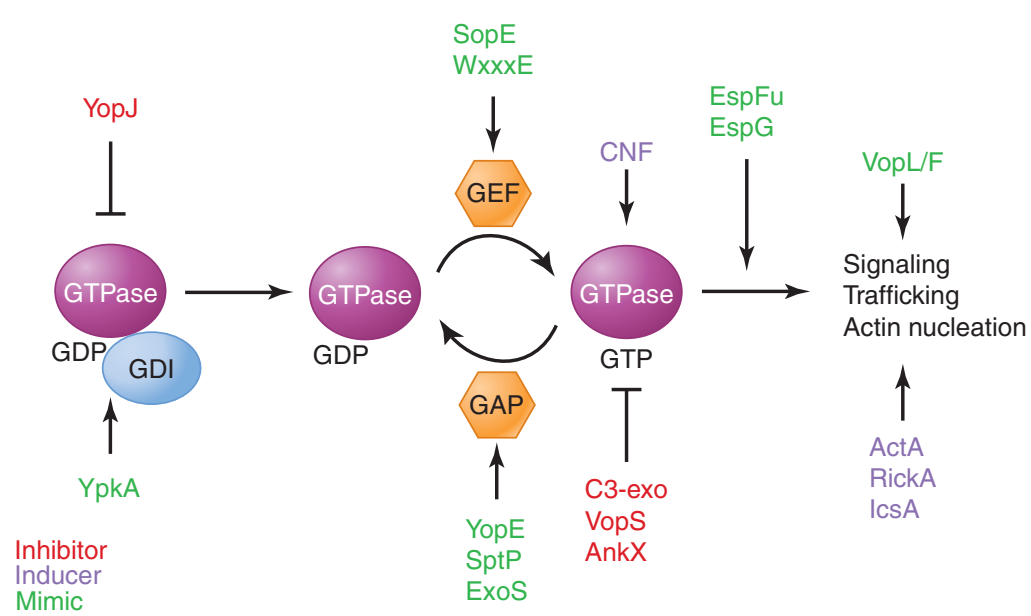

Figure 4. Multilevel regulation of small G proteins by bacterial effectors. Small G proteins cycle on and off membranes, exchange guanine nucleotides (GDP to GTP) for activation, hydrolyze GTP for inactivation, and stimulate downstream signaling pathways. Bacterial pathogens have evolved toxins and effector proteins to usurp nearly every aspect of small G-protein function, using molecular mimicry as well as novel stimulatory and inhibitory mechanisms. 
similar nucleotide-free transition states essential for guanine-nucleotide exchange. The catalytic loops of bacterial GEFs are important for making contacts with the switch I and switch II regions of the host small G proteins. Recent studies have shown that these loops are flexible and that proper orientation is important for small G-protein recognition and activation (Klink et al. 2010). Reorientation of the catalytic loop may therefore be a mechanism for bacterial GEFs to control host small G-protein activity in response to bacterial or host stimuli.

\subsection{Bacterial GTPase-Activating Protein (GAP) Mimics}

Many pathogens have evolved proteins that directly engage small $\mathrm{G}$ proteins and stimulate GTP hydrolysis, thus turning the molecular switch off. A key example of this activity is the YopE protein from Yersinia pseudotuberculosis (Fig. 4). YopE has in vitro GAP activity toward RhoA, Rac1, and Cdc42 (Black and Bliska 2000; Von Pawel-Rammingen et al. 2000; Andor et al. 2001). It engages the small G proteins directly and presents a critical arginine residue (R144) that stabilizes the $\beta$ phosphate of the GTP moiety, thus increasing the hydrolytic rate. In fact, mutant bacteria expressing YopE (R144A) that lacks GAP activity are incapable of inducing cytotoxicity. During a Yersinia infection, YopE works in concert with YopH to prevent phagocytosis by the host cell. The former effector induces collapse of the actin cytoskeleton and rounding of the host cell, whereas the latter effector disassembles focal adhesions (see above).

Salmonella spp. subvert host small G proteins to gain entry into normally nonphagocytic cells, such as intestinal epithelial cells. It induces its own engulfment by injecting proteins like SopE that reorganize the actin cytoskeleton (discussed above). The type III secreted SptP protein uses a tyrosine phosphatase activity and Rho-GTPase GAP activity in order to return the cytoskeleton back to a preinvasion state (Fu and Galan 1999; Stebbins and Galan 2000). Much like YopE from Yersinia, SptP from Salmonella has an "arginine finger" that induces efficient GTP hydrolysis by small $G$ proteins. Interestingly, the temporal shift in activity between actin-polymerization-promoting factors such as SopE and actin inhibitors such as SptP is dictated by ubiquitin-dependent degradation (Kubori and Galan 2003). Degradation of SopE allows SptP to rapidly inhibit nonspecific Rho-family GTPase signaling, thus preventing spurious actin assembly so that immune cells no longer detect intracellular Salmonella.

Finally, Pseudomonas, an opportunistic, extracellular pathogen associated with severe infection in cystic fibrosis patients and burn patients, expresses the effector protein ExoS, which contains two catalytic domains that inhibit small G proteins. The first is an ADP-ribosyltransferase domain that transfers ADP-ribose from $\mathrm{NAD}^{+}$to $\mathrm{R} 41$ of several Ras-like small G proteins (Coburn et al. 1989; Coburn and Gill 1991). This activity uncouples signaling by preventing GEF-mediated activation of small G proteins. The second is a GAP domain that potently inactivates several host small G proteins (Goehring et al. 1999). Whereas many bacterial effector proteins have evolved to specifically target a particular small $\mathrm{G}$ protein, ExoS functions to perturb the activation of multiple GTP-binding proteins and thus the signal transduction pathways they control (Henriksson et al. 2002). Together, the down-regulation of small G-protein signaling by bacterial GAPs dampens actin cytoskeleton dynamics at the bacterium-host interface.

\subsection{A Yersinia Protease Destroys the Small G-Protein Membrane Anchor}

The Yersinia effector protein YopT can disrupt the actin cytoskeleton, causing rounding up of host cells, and thereby inhibit phagocytosis (Fig. 4) (Iriarte and Cornelis 1998). YopT is a cysteine protease that cleaves amino-terminally to the prenylated cysteine residue in RhoA, Rac, and Cdc42 (Shao et al. 2002, 2003). This liberates Rho proteins from the membrane and irreversibly inhibits signaling to the actin cytoskeleton. YopT is similar to papain proteases and recognizes basic amino acid residues upstream of the cleavage site as well as both the GDP-bound and GTP-bound forms of RhoA. Thus, cleavage does not depend on the conformational state of the small G-protein. When RhoA is no longer tethered to the membrane, actinmediated cytoskeletal responses during infection are effectively thwarted.

\subsection{Yersinia YpkA: A Kinase and a GDI}

Another Yersinia effector protein that regulates host membrane remodeling is YpkA. This three-domain effector contains an amino-terminal kinase domain, central guanine nucleotide dissociation inhibitor (GDI) domain, and a carboxy-terminal actin-binding domain (Juris et al. 2000; Prehna et al. 2006). YpkA preferentially phosphorylates the active GTP-bound form of the $\alpha_{\mathrm{q}}$ heterotrimeric G-protein subunit at position $S 47$ (Navarro et al. 2007). This modification prevents $\alpha_{\mathrm{q}}$ from binding GTP, thereby inhibiting its activity and the subsequent membrane remodeling that would otherwise enhance uptake of bacteria. Interestingly, mice with deficiencies in $\alpha_{\mathrm{q}}$ function have increased bleeding times and defective platelet activation, which is a hallmark of the Plague (Offermanns et al. 1997).

The central GDI domain in YpkA from Yersinia directly binds Racl and mimics the host GDI for Rho small G 
proteins (Prehna et al. 2006). Consequently, Racl cannot undergo GDP for GTP exchange and localization to the membrane, where it would normally function in cell adhesion, migration, and regulation of epithelial cell differentiation.

\subsection{Bacterial Effectors Can Modify Small G Proteins}

As indicated above, Rho family small $G$ proteins are highvalue targets for bacterial effector proteins because they control the eukaryotic cytoskeleton. Therefore, unsurprisingly, some bacterial effector proteins not only mimic the endogenous regulators but can posttranslationally modify eukaryotic small G proteins (Etienne-Manneville and Hall 2002). C3 toxin from Clostridium botulinum, more generically known as botulinum toxin, has evolved the ability to ADP-ribosylate and inactivate Rho-family small G proteins, specifically RhoA, RhoB, and RhoC, on an invariant N41 residue (Mohr et al. 1992). Treatment of adherent cells with C3 toxin results in the disassembly of actin microfilaments and rounding up of cells (Chardin et al. 1989). N41 is located at the border of the switch I region of Rho-family proteins, and ADP ribosylation induces close association of the Rho small $G$ protein with its cognate GDI, thereby inhibiting cytosol-to-membrane cycling and preventing activation by GEFs (Sehr et al. 1998). Bacteria with extracellular life cycles, like E. coli, must avoid phagocytosis. This can be accomplished through covalent modification of Rho, Rac, and Cdc42. Specifically, cytotoxic necrotizing factor 1 (CNF1) deamidates Q63 of Rho or Q61 of Rac and Cdc42 (Flatau et al. 1997; Schmidt et al. 1997). By removing the functional amine group from the critical catalytic glutamine residue, this renders the small $\mathrm{G}$ protein constitutively active. Deamination-induced activation of these small $G$ proteins results in cell ruffling and the formation of stress fibers, focal adhesions, and lamellipodia, as well as extension of filopodia. These effects lead to unregulated membrane protrusions that appear to inhibit normal phagocytic events. An additional interesting feature of CNF1 is its ability to rescue epithelial cells from apoptosis, presumably prolonging the infectivity of the pathogenic bacterium (Miraglia et al. 2007).

Another posttranslational modification used by bacterial effectors is AMPylation, covalent attachment of AMP to a hydroxyl side chain on a protein substrate (Woolery et al. 2010). In the 1960s, Earl Stadtman and colleagues found that E. coli glutamine synthetase is regulated by glutamine synthetase adenylyl transferase (GS-ATase), a bifunctional enzyme that catalyzes addition and removal of AMP from glutamine synthetase. This results in inactivation and activation of the enzyme, respectively, which permits cellular regulation of nitrogen metabolism (Brown et al. 1971). VopS, a T3SS effector protein from $V$. parahaemolyticus, which causes gastroenteritis due to consumption of contaminated raw seafood, has been found to AMPylate the conserved threonine residue in the switch I region of Rho. The AMPylated small G protein can no longer bind to downstream substrates such as PAK and rhotekin, which results in disorganization of the actin cytoskeleton (Yarbrough et al. 2009). This benefits the pathogen because the host cell's actin assembly machinery is compromised, and it can no longer induce phagocytosis.

Bacterial pathogens use AMPylators to disrupt host signaling pathways to promote bacterial survival and replication (for review, see Woolery et al. 2010). IbpA secreted from Histophilus somni, like VopS, also modifies RhoA with AMP but on a tyrosine residue instead of a threonine in the switch I region (Worby et al. 2009). Both VopS and IpbA proteins contain a Fic domain (Filamentation induced by cAMP) that mediates this enzymatic activity. The Fic and doc domains share a conserved $\operatorname{HPFx}[\mathrm{D} / \mathrm{E}] \mathrm{GN}[\mathrm{G} / \mathrm{K}] \mathrm{R}$ motif, in which the invariant histidine residue is essential for AMPylation activity in Fic proteins (Luong et al. 2010) and cytotoxicity in doc (Garcia-Pino et al. 2008). Indeed, the two domains are grouped in the same family and classified as FIDO domains based on structural similarities (Kinch et al. 2009). Interestingly, Fic domains, found in bacteria, archaea, and metazoans, are thought to function as endogenous signaling elements and, therefore, are regulated so as not to cause harm to the host (Kinch et al. 2009; Engel et al. 2012). Indeed, 90\% of Fic domains are regulated by an inhibitory $\alpha$-helix that prevents constitutive binding of ATP, and binding of a specific substrate is predicted to relieve this inhibition to allow AMPylation (Engel et al. 2012). AMPylators are comparable to kinases in that they both hydrolyze ATP and reversibly transfer a part of this metabolite onto a hydroxyl side chain of the protein substrate.

A more specialized Fic domain can use the substrate CDP-choline, instead of ATP, in a phosphotransfer reaction, producing small $G$ proteins modified by a phosphocholine moiety (Mukherjee et al. 2011). Legionella, causal agent of Legionnaires' disease, produces the effector AnkX, which contains an Fic domain that modifies Rab1 (a host small G protein involved in membrane transport) at its switch II region with phosphocholine. The modified $\mathrm{Rab} 1$ is no longer recognized by the host GEF, connecdenn, but can bind to and be activated by the Legionella GEF DrrA. The inactivation and activation of Rab1 on Legionella-containing vacuoles (LCVs) thus become dictated by the pathogen by posttranslational modifications of Rab GTPases.

The adenylyl transferase domain is part of the larger nucleotidyl transferase domain family and, like Fic domains, can catalyze AMPylation. It is characterized by a 
conserved $\mathrm{Gx}_{11} \mathrm{DxD}$ motif in which the aspartate residues are essential for the AMPylation activity (Jiang et al. 2007; Muller et al. 2010). This domain has been identified in more than 1400 bacterial proteins among 685 bacterial species, of which the large majority are proteobacteria (Finn et al. 2009).

DrrA (also known as SidM) is a virulence factor secreted from Legionella, an intracellular pathogen that survives in LCVs in the cell (Muller et al. 2010). Legionella uses a T4SS to secrete proteins from the LCV into the host cell. DrrA is composed of three domains: an amino-terminal adenylyl transferase domain, a GEF domain, and a carboxy-terminal phosphatidylinositol-4-phosphate-binding (P4M) domain (Murata et al. 2006; Brombacher et al. 2009). The first domain of DrrA very closely resembles the carboxy-terminal adenylyl transferase domain of $E$. coli GS-ATase and contains the conserved $\mathrm{Gx}_{11} \mathrm{DxD}$ motif (Muller et al. 2010). The GEF domain is capable of catalyzing the exchange of GDP for GTP on Rab1, which plays a role in the regulation of vesicular transport from the endoplasmic reticulum (Murata et al. 2006). The P4M domain anchors the effector to the cytoplasmic side of the LCV membrane (Brombacher et al. 2009). DrrA hijacks Rab1 by locking it into its GTP-bound active state, using both the DrrA GEF and adenylyl transferase domains. The GEF domain exchanges GDP for GTP, and the adenylyl transferase domain AMPylates Y77 in the switch II region of Rab1, which blocks its interaction with host GAPs, preventing the hydrolysis of GTP. AMPylated and prenylated GTPRab1 localizes with DrrA and targets ER vacuoles to the LCV (Muller et al. 2010). Another virulence factor from Legionella, SidD, contains a deAMPylating activity, allowing its recycling (Neunuebel et al. 2011; Tan and Luo 2011). This protein is a phosphodiesterase that, on the basis of structural analysis, resembles a protein phosphatase (Rigden 2011).

\subsection{Bacterial Effectors Mimic Host Small G Proteins}

Another strategy used by bacterial pathogens is to produce proteins that mimic small $\mathrm{G}$ proteins themselves. EHEC O157:H7 secretes the effector protein EspFu (also known as $\mathrm{TccP}$ ) in order to create actin-based pedestals, allowing attachment of the bacterium to the intestinal epithelium (Campellone et al. 2004; Garmendia et al. 2004). The Wiskott-Aldrich syndrome protein (WASP) family of actin nucleators is normally regulated by Rac and Cdc42, which bind to the Cdc42/Rac1-interaction-binding domain (CRIB) motif within the G-protein-binding domain (GBD) of N-WASP (Devreotes and Horwitz 2012). This releases N-WASP from an autoinhibited conformation that depends on interaction of the GBD and the verprolin- homology, cofilin-homology, acidic (VCA) domain. Remarkably, EspFu mimics a 17-residue stretch of the VCA motif, thus competing for binding with the GBD, and thereby constitutively activates N-WASP and activates downstream actin polymerization (Cheng et al. 2008; Sallee et al. 2008).

EspFu is not the only bacterial effector to directly activate small G-protein substrates. A second EHEC O157:H7 effector, EspG, is an activator of class I PAK family serine/ threonine kinases (Selyunin et al. 2011). Under normal circumstances, PAKs are responsible for regulating cytoskeletal dynamics and are activated by Rac1 or Cdc42 small $G$ proteins in a manner similar to the activation of N-WASP discussed above. The PAKs contain an amino-terminal autoinhibitory domain and a carboxy-terminal kinase domain. Binding of activated Cdc42 or Racl to the CRIB domain within the autoinhibitory domain of PAK potently induces kinase activation. In contrast, EHEC EspG binds to and activates PAK but does not recognize the CRIB. Rather, EspG specifically interacts with the I $\alpha 3$ helix, which sits upstream of the CRIB domain and serves two primary functions: (1) it occludes the substrate-binding site of the kinase domain, and (2) it positions an inhibitory loop into the kinase catalytic cleft. Binding of EspG to I $\alpha 3$ is predicted to unfold the autoinhibitory domain and release the kinase inhibitory loop, leading to PAK activation. Both bacterial virulence factors, EspFu and EspG, thus mimic the basic principles of host small G-protein function to activate their downstream targets by separating the inhibitory domain from the activity-bearing domain, but they use distinct molecular mechanisms to achieve this result.

\section{HIGHJACKING LIPID SIGNALING}

Phosphoinositides, particularly phosphatidylinositol 4,5bisphosphate $\left(\mathrm{PIP}_{2}\right)$, regulate the actin cytoskeleton beneath the plasma membrane, functioning in signaling as well as trafficking by targeting vesicles around the cell. Disruption of phosphoinositide homeostasis at the plasma membrane by bacterial effectors can destabilize actin dynamics and alter the morphology of the membrane. This facilitates the entry of intracellular pathogens or, in the case of extracellular pathogens, can disrupt membrane integrity, which leads to rapid cell lysis in the subsequent stage of infection to facilitate pathogen spreading (Ham et al. 2011).

\subsection{The Inositol Polyphosphate 4-Phosphatase Shigella IpgD and Salmonella SopB Promote Pathogen Entry}

IpgD is an effector from the facultative intracellular pathogen Shigella that is directly translocated into host cells 
through a T3SS upon contact with the cell surface (Niebuhr et al. 2000). IpgD is a 4-phosphoinositide phosphatase that hydrolyzes $\mathrm{PIP}_{2}$ to produce phosphatidylinositol 5-phosphate [PI(5)P] (Niebuhr et al. 2002). Removal of $\mathrm{PIP}_{2}$ by IpgD decreases the tethering of the plasma membrane to $\mathrm{PIP}_{2}$-binding cytoskeleton-anchoring proteins, causing extension of membrane filopodia and massive cellular blebbing (observed as bubble-like protrusions) (Charras and Paluch 2008). This reorganization of the actin cytoskeleton at the bacterial entry site promotes the uptake of the pathogen by the host cells.

Like IpgD, the Salmonella effector protein SopB hydrolyzes $\mathrm{PIP}_{2}$ to promote bacterial invasion and establish a niche for its vacuolar life cycle inside the host (Norris et al. 1998; Terebiznik et al. 2002; Hernandez et al. 2004). Thus, modulation of phosphoinositide metabolism appears to be a common strategy for bacterial pathogens to usurp signaling at plasma and vesicular membranes.

\subsection{Inositol Polyphosphate 5-Phosphatase V. parahaemolyticus VPA0450 Promotes Blebbing}

A similar molecular mechanism is used by the T3SS effector VPA0450 from the extracellular pathogen V. parahaemolyticus (Broberg et al. 2010). VPA0450 contains catalytic motifs that mimic the activity of the eukaryotic inositol polyphosphate 5-phosphatases (IPP5Cs), which hydrolyze $\mathrm{PIP}_{2}$ at the membrane surface. In contrast to IpgD, VPA0450 hydrolyzes the D5 phosphate, producing PI(4)P. The removal of $\mathrm{PIP}_{2}$ disrupts actin dynamics, causing the local detachment of the cortical cytoskeleton from the plasma membrane, which leads to extensive membrane blebbing. Whereas IpgD uses the same molecular mechanism to facilitate internalization of the bacteria, blebbing induced by VPA0450 instead accelerates lysis of the infected host cell (Broberg et al. 2011).

\section{OTHER ACTIN REGULATORS TARGETED BY PATHOGENS}

The actin cytoskeleton supports focal adhesions and controls cell contraction, cell motility, endocytosis, phagocytosis, and cell division. A characteristic feature of all of these processes is the dynamic transition of cellular actin between its monomeric $(\mathrm{G})$ and polymeric $(\mathrm{F})$ actin states, which is controlled by a myriad of regulatory proteins that act on distinct states of the actin polymer network. For example, the Arp 2/3 complex nucleates filaments that grow from the side of existing filaments, creating branched networks, whereas formins and SPIRE nucleate unbranched filaments (Campellone and Welch 2010). A common mechanistic feature of all three systems is the ability to assemble actin or actin-like proteins into an arrangement that can serve as a template for growth of a new filament. The Arp2/3 complex contains two actin-related subunits, which form a pseudo-actin trimer with an actin monomer provided by activators of the WASP family, such as N-WASP (see above). Formins bind two actin monomers and are thought to position them appropriately for filament growth. SPIRE proteins have multiple repeats of Wiskott-Aldrich homology 2 (WH2) domains that bind to actin and appear to create a three-actin template for filament extension. Bacteria and viruses can hijack these mechanisms to directly regulate actin nucleation, producing the characteristic pathogen motility observed in Listeria-, Shigella-, Rickettsia-, and Vaccinia-virus-infected cells. In addition, several bacterial species from the Vibrio genus translocate actinelongation factors into host cells.

\subsection{Pathogenic Actin Nucleation Factors}

A few bacterial pathogens and viruses use actin polymerization to move around within and between cells. Bacteria from at least three genera (Listeria, Shigella, and Rickettsia) and Vaccinia virus all use membrane-anchored proteins to produce actin comet tails that propel the microorganism through the cytoplasm, along the surface of the cell, or through the plasma membrane into a neighboring cell. Although the proteins used by each of these pathogens are unique in structure and function, they all share the common feature of nucleating actin filaments de novo at the membrane surface. For example, ActA directly recruits and activates the Arp2/3 complex at the surface of Listeria monocytogenes (Welch et al. 1998). It has, in fact, been an essential tool for studies of various biological processes including cell motility and provided the first physiological evidence for the nucleating activity of the Arp2/3 complex (Welch et al. 1998). Like ActA, Shigella VirG/IcsA induces formation of actin comet tails, but this pathogen uses a distinct mechanism. Whereas ActA directly activates $\operatorname{Arp} 2 / 3, \operatorname{VirG} /$ IcsA on the bacterial surface can recruit N-WASP and induce actin nucleation via Arp2/3 (Egile et al. 1999). Finally, Vaccinia virus uses the membrane-anchored protein A36R to facilitate intracellular movement that is strikingly similar. A large domain of A36R on the viral surface is phosphorylated by Src-family tyrosine kinases and then directly interacts with the adaptor protein Nck and subsequently recruits N-WASP. These processes are all essential for the bacteria and viruses to invade systemic tissues of their host organism and therefore represent key virulence factors in a wide range of infectious diseases.

Extracellular pathogens including EPEC also hijack Arp2/3, albeit by a mechanism distinct from that described 
above. EPEC secretes a cell surface receptor, Tir, which embeds in the host plasma membrane and forms a complex with the bacterial adhesion molecule intimin (Kenny et al. 1997). This causes Tir to cluster at the cell surface, resulting in tyrosine phosphorylation of its cytoplasmic tail and subsequent recruitment of Nck via its $\mathrm{SH} 2$ domain (Gruenheid et al. 2001). This recruits N-WASP and the Arp2/3 complex to nucleate branched actin filaments at the EPEC-host interface, resulting in the formation of pedestals. These molecular events are instrumental in the tight attachment of EPEC to the intestinal epithelial cell wall and also induce the characteristic attaching and effacing (A/E) lesion that defines EPEC infections.

\subsection{Pathogenic Elongation Factors: Vibrio VopL/F}

In addition to inducing branched actin networks through activation of Arp2/3, V. parahaemolyticus produces VopL, which has three closely spaced WH2 domains that bind actin (Fig. 4) (Liverman et al. 2007). VopL directly induces the nucleation of actin independently of any other eukaryotic factor and is more efficient than its eukaryotic counterparts (Namgoong et al. 2011; Yu et al. 2011). Interspersed with the WH2 domains are three proline-rich motifs (PRMs). PRMs have many potential interacting partners, including WW domains, $\mathrm{SH} 3$ domains, and the actin-binding protein profilin. The PRMs in VopL closely resemble those found in the FH1 domains of formins, which are known to bind profilin and profilin-actin complexes (Holt and Koffer 2001). V. parahaemolyticus uses VopL to induce unregulated production of stress fibers and thereby disrupts actin homeostasis in the epithelial cells of the gut during infection, resulting in an enterotoxic effect in the intestine. Another T3SS virulence factor from V. cholera, VopF, contains a similar WH2/PRM domain architecture and also promotes actin assembly independently of host proteins. VopF induces the formation of small actin protrusions, rather than stress fibers, and may help efficient colonization during infection.

\section{TARGETING UBIQUITIN-MEDIATED SIGNAL TRANSDUCTION}

Evolutionarily conserved ubiquitylation machinery regulates a diverse set of cellular processes, including development, transcription, replication, cell signaling, and immune function (Pickart 2004; Mukhopadhyay and Riezman 2007; Yaffe 2012). The versatility of this system to reversibly modify protein function makes it an attractive target for a wide range of pathogens, including viruses and bacteria. These microbes are particularly adept at coopting the ubiquitylation machinery. Indeed, ubiquitin itself is encoded by a large number of viral genomes, and many viruses and bacteria encode the ubiquitin ligases or adaptor proteins required for ubiquitin posttranslational modification (Randow and Lehner 2009; Collins and Brown 2010).

Ubiquitin can be covalently linked to protein substrates as either a single molecule (monoubiquitylation) or a polypeptide chain (polyubiquitylation) (Yaffe 2012). It is first activated by a ubiquitin-activating enzyme, E1, which involves an ATP-dependent transfer of ubiquitin to the enzyme's catalytic cysteine residue. It is then transferred to the active-site cysteine of an E2 ubiquitin-conjugating enzyme. The ubiquitin residue on the charged E2 enzyme is then targeted to substrates via an E3 ligase. K48-linked chains of ubiquitin mark the substrate for proteasomal degradation. In contrast, monoubiquitylation or K63-linked chains serve as regulatory signals in signal transduction, membrane trafficking, DNA repair, and chromatin remodeling. Below, we highlight a few specific examples of pathogens exploiting the ubiquitin system. These interactions have not only informed us regarding microbial pathogenesis, but also continue to reveal novel mechanisms of ubiquitin regulation in cell signaling.

Many viruses, including baculoviruses, poxviruses, and herpes simplex virus, encode their own ubiquitin molecules but have significantly altered the ubiquitin gene. $\mathrm{Hu}-$ man ubiquitin shares only $75 \%$ similarity with baculovirus ubiquitin, compared with $96 \%$ similarity with yeast ubiquitin (Haas et al. 1996). The viral ubiquitylation machinery may therefore function differently from the host ubiquitylation machinery. Many bacteria also secrete enzymes that modify host ubiquitin or ubiquitin-like molecules (UBLs). Recent studies of EPEC revealed that host ubiquitin is deamidated on Q40 by the bacterial type III effector Cif (Cui et al. 2010). Similarly, the Cif homolog CHBP encoded by Burkholderia pseudomallei deamidates Q40 both on ubiquitin and the UBL Nedd8 (Cui et al. 2010; Jubelin et al. 2010; Morikawa et al. 2010). These posttranslational modifications potently inhibit polyubiquitin chain synthesis, resulting in accumulation of host substrates and severe cytopathic effects.

Viruses and bacteria can also encode their own E3 ubiquitin ligases or adaptor proteins that link host E3 enzymes to specific host substrates. Most known eukaryotic E3 ligases belong to one of three types: RING, HECT, and U-box. There are currently no known viral HECT family E3 ubiquitin ligases. Instead, viruses encode RING family or unconventional E3 ligases. Two examples of RING type E3 ligases are the RING-CH family and the Infected Cell Protein 0 (ICP0) family. Initially identified in the murine and human gammaherpes viruses, respectively, these virulence factors down-regulate immune cell surface receptors (Coscoy and Ganem 2000; Ishido et al. 2000; Stevenson et al. 
2000; Haque et al. 2001). For example, the K3 and K5 gene products of Karposi's Sarcoma Associated Herpesvirus (KSHV) provide immune protection by ubiquitylating MHC class I molecules that present antigen at the cell surface, targeting them for endocytosis and lysosomal degradation. In contrast, ICP0 of herpes simplex virus type I (HSV-1) is required for reactivation of latency and suppression of innate immunity (Everett 2000). The RING domain of ICP0 promotes the accumulation of ubiquitylated proteins and their subsequent proteasomal degradation. In particular, it causes the degradation of RNF8 and RNF168, host cell E3 ligases that are essential for the cellular response to DNA damage. By degrading these proteins, ICP0 blocks the cellular DNA damage response that HSV infection activates, which would otherwise shut off viral transcription.

Another well-characterized example of a virally encoded E3 ligase is adenovirus E4orf6, which, together with adenovirus E1B-55K, substitutes for the substrate recognition subunits of the cullin-EloB-C core complex (Querido et al. 2001a). This host-pathogen complex forms a novel ubiquitin ligase that targets the tumor suppressor p53, Mre11, and the BLM helicase to abrogate the cellular DNA damage response during viral infection (Dobner et al. 1996; Querido et al. 2001b).

The KSHV immediate-early transcription factor RTA shows unconventional E3 ubiquitin ligase activity that targets host immune protein IRF7 for proteasomal degradation (Yu et al. 2005). Similarly, the ubiquitin ligase domain of the IpaH family of bacterial type III effectors is structurally distinct from both the HECT and RING families (Rohde et al. 2007; Singer et al. 2008; Zhu et al. 2008). However, like the HECT-type E3 ligases, IpaH transfers ubiquitin from UbcH5 E2 to substrates by forming a ubiquitin thioester intermediate at a conserved cysteine residue. A series of leucine-rich repeats (LRRs) in IpaH and its family members is responsible for recognizing a diverse array of host substrates and targeting these substrates for ubiquitylation.

Pathogens may also encode adaptor proteins that link E3 ligases to target substrates. In a classic example, the E6 oncoprotein encoded by human papillomavirus (HPC) facilitates ubiquitylation and proteasomal degradation of p53 (Scheffner et al. 1993; Huibregtse et al. 1995). The dimeric E6 forms a complex with human E6-AP, the founding member of the HECT-type E3 ubiquitin ligase family (Huibregtse et al. 1995). The E6-E6-AP complex binds to and targets p53 for ubiquitin-dependent proteolysis, thus interfering with the growth-regulating activities of this tumor suppressor. These discoveries have provided essential insights into cancer caused by high-risk HPV, and have defined an entire class of E3 ubiquitin ligases involved in a myriad of biological processes.

\section{CONCLUSION}

Virulence factors produced by pathogens have evolved to efficiently manipulate host signaling pathways (Table 1). Mechanisms range from constitutive activation of a pathway, to irreversible inactivation of a critical signaling molecule, to subversion of a whole signaling system to favor the invading pathogen. A major challenge in the future is to determine the enzymatic activities and host substrates for the bacterial and viral virulence factors that show no obvious homology to eukaryotic proteins. Another, even more complex challenge is to understand how these factors work together to orchestrate a successful infection. Temporal and spatial considerations are extremely important for regulating a host cell during infection. Likewise, within the pathogen, determining the regulatory mechanisms that control the activation patterns and spatial dynamics of virulence factors will help reveal how microbial pathogens coopt signal transduction systems during infection. Finally, the use of model organisms to complement studies in mammalian cells will provide valuable insights into the physiological roles of bacterial effector proteins. Such information is essential to gain a system-level view of the infectious disease process and to ultimately design therapeutics that target host-pathogen interactions. Inevitably, by discovering the mechanisms of pathogenic effectors, we have gained a greater understanding into critical steps in eukaryotic signaling. Although a great deal has been learned, given the number and diversity of the yet-to-be-studied bacterial and viral pathogens, much more is left to be discovered.

\section{REFERENCES}

* Reference is also in this collection.

Alto NM, Shao F, Lazar CS, Brost RL, Chua G, Mattoo S, McMahon SA, Ghosh P, Hughes TR, Boone C, et al. 2006. Identification of a bacterial type III effector family with $G$ protein mimicry functions. Cell 124: $133-145$.

Andor A, Trulzsch K, Essler M, Roggenkamp A, Wiedemann A, Heesemann J, Aepfelbacher M. 2001. YopE of Yersinia, a GAP for Rho GTPases, selectively modulates Rac-dependent actin structures in endothelial cells. Cell Microbiol 3: 301-310.

Black DS, Bliska JB. 2000. The RhoGAP activity of the Yersinia pseudotuberculosis cytotoxin YopE is required for antiphagocytic function and virulence. Mol Microbiol 37: 515-527.

Broberg CA, Zhang L, Gonzalez H, Laskowski-Arce MA, Orth K. 2010. A Vibrio effector protein is an inositol phosphatase and disrupts host cell membrane integrity. Science 329: 1660-1662.

Broberg CA, Calder TJ, Orth K. 2011. Vibrio parahaemolyticus cell biology and pathogenicity determinants. Microbes Infect 13: 992-1001.

Brombacher E, Urwyler S, Ragaz C, Weber SS, Kami K, Overduin M, Hilbi H. 2009. Rab1 guanine nucleotide exchange factor SidM is a major phosphatidylinositol 4-phosphate-binding effector protein of Legionella pneumophila. J Biol Chem 284: 4846-4856.

Brown MS, Segal A, Stadtman ER. 1971. Modulation of glutamine synthetase adenylylation and deadenylylation is mediated by metabolic 
transformation of the P II -regulatory protein. Proc Natl Acad Sci 68: 2949-2953.

Buchwald G, Friebel A, Galan JE, Hardt WD, Wittinghofer A, Scheffzek K. 2002. Structural basis for the reversible activation of a Rho protein by the bacterial toxin SopE. EMBO J 21: 3286-3295.

Campellone KG, Welch MD. 2010. A nucleator arms race: Cellular control of actin assembly. Nat Rev 11: 237-251.

Campellone KG, Robbins D, Leong JM. 2004. EspFU is a translocated EHEC effector that interacts with Tir and N-WASP and promotes Nckindependent actin assembly. Dev Cell 7: 217-228.

Chardin P, Boquet P, Madaule P, Popoff MR, Rubin EJ, Gill DM. 1989. The mammalian G protein rhoC is ADP-ribosylated by Clostridium botulinum exoenzyme $\mathrm{C} 3$ and affects actin microfilaments in Vero cells. EMBO J 8: 1087-1092.

Charras G, Paluch E. 2008. Blebs lead the way: How to migrate without lamellipodia. Nat Rev 9: 730-736.

Cheng HC, Skehan BM, Campellone KG, Leong JM, Rosen MK. 2008. Structural mechanism of WASP activation by the enterohaemorrhagic E. coli effector EspF(U). Nature 454: 1009-1013.

Coburn J, Gill DM. 1991. ADP-ribosylation of $\mathrm{p} 21^{\text {ras }}$ and related proteins by Pseudomonas aeruginosa exoenzyme S. Infect Immun 59: 42594262.

Coburn J, Wyatt RT, Iglewski BH, Gill DM. 1989. Several GTP-binding proteins, including $\mathrm{p} 21 \mathrm{c}-\mathrm{H}$-ras, are preferred substrates of Pseudomonas aeruginosa exoenzyme S. J Biol Chem 264: 9004-9008.

Collier RJ. 2009. Membrane translocation by anthrax toxin. Mol Aspects Med 30: 413-422.

Collins CA, Brown EJ. 2010. Cytosol as battleground: Ubiquitin as a weapon for both host and pathogen. Trends Cell Biol 20: 205-213.

Coscoy L, Ganem D. 2000. Kaposi's sarcoma-associated herpesvirus encodes two proteins that block cell surface display of MHC class I chains by enhancing their endocytosis. Proc Natl Acad Sci 97: 8051-8056.

Cui J, Yao Q, Li S, Ding X, Lu Q, Mao H, Liu L, Zheng N, Chen S, Shao F. 2010. Glutamine deamidation and dysfunction of ubiquitin/NEDD8 induced by a bacterial effector family. Science 329: 1215-1218.

* Devreotes P, Horwitz A. 2012. Signal transduction and the regulation of cell migration. Cold Spring Harb Perspect Biol doi: 10.1101/ cshperspect.a005959.

Dobner T, Horikoshi N, Rubenwolf S, Shenk T. 1996. Blockage by adenovirus E4orf6 of transcriptional activation by the p53 tumor suppressor. Science 272: 1470-1473.

Egile C, Loisel TP, Laurent V, Li R, Pantaloni D, Sansonetti PJ, Carlier MF. 1999. Activation of the CDC42 effector N-WASP by the Shigella flexneri IcsA protein promotes actin nucleation by Arp2/3 complex and bacterial actin-based motility. J Cell Biol 146: 1319-1332.

Engel P, Goepfert A, Stanger FV, Harms A, Schmidt A, Schirmer T, Dehio C. 2012. Adenylylation control by intra- or intermolecular active-site obstruction in Fic proteins. Nature 482: 107-110.

Etienne-Manneville S, Hall A. 2002. Rho GTPases in cell biology. Nature 420: 629-635.

Everett RD. 2000. ICP0, a regulator of herpes simplex virus during lytic and latent infection. Bioessays 22: 761-770.

Finn RD, Mistry J, Tate J, Coggill P, Heger A, Pollington JE, Gavin OL, Gunasekaran P, Ceric G, Forslund K, et al. 2009. The Pfam protein families database. Nucleic Acids Res 38: D211-D222.

Flatau G, Lemichez E, Gauthier M, Chardin P, Paris S, Fiorentini C, Boquet P. 1997. Toxin-induced activation of the G protein $\mathrm{p} 21$ Rho by deamidation of glutamine. Nature 387: 729-733.

Fu Y, Galan JE. 1999. A Salmonella protein antagonizes Rac-1 and Cdc42 to mediate host-cell recovery after bacterial invasion. Nature 401: 293-297.

Garcia-Pino A, Christensen-Dalsgaard M, Wyns L, Yarmolinsky M, Magnuson RD, Gerdes K, Loris R. 2008. Doc of prophage P1 is inhibited by its antitoxin partner Phd through fold complementation. J Biol Chem 283: 30821-30827.

Garmendia J, Phillips AD, Carlier MF, Chong Y, Schuller S, Marches O, Dahan S, Oswald E, Shaw RK, Knutton S, et al. 2004. TccP is an enterohaemorrhagic Escherichia coli O157:H7 type III effector protein that couples Tir to the actin-cytoskeleton. Cell Microbiol 6: 11671183.

Goehring UM, Schmidt G, Pederson KJ, Aktories K, Barbieri JT. 1999. The N-terminal domain of Pseudomonas aeruginosa exoenzyme $\mathrm{S}$ is a GTPase-activating protein for Rho GTPases. J Biol Chem 274: 36369-36372.

Gruenheid S, DeVinney R, Bladt F, Goosney D, Gelkop S, Gish GD, Pawson T, Finlay BB. 2001. Enteropathogenic E. coli Tir binds Nck to initiate actin pedestal formation in host cells. Nat Cell Biol 3: 856-859.

Guan KL, Dixon JE. 1990. Protein tyrosine phosphatase activity of an essential virulence determinant in Yersinia. Science 249: 553-556.

Haas AL, Katzung DJ, Reback PM, Guarino LA. 1996. Functional characterization of the ubiquitin variant encoded by the baculovirus Autographa californica. Biochemistry 35: 5385-5394.

Ham H, Sreelatha A, Orth K. 2011. Manipulation of host membranes by bacterial effectors. Nat Rev Microbiol 9: 635-646.

Hao YH, Wang Y, Burdette D, Mukherjee S, Keitany G, Goldsmith E, Orth K. 2008. Structural requirements for Yersinia YopJ inhibition of MAP kinase pathways. PLoS ONE 3: e1375.

Haque M, Ueda K, Nakano K, Hirata Y, Parravicini C, Corbellino M, Yamanishi K. 2001. Major histocompatibility complex class I molecules are down-regulated at the cell surface by the K5 protein encoded by Kaposi's sarcoma-associated herpesvirus/human herpesvirus-8. J Gen Virol 82: 1175-1180.

Hardt WD, Chen LM, Schuebel KE, Bustelo XR, Galan JE. 1998. $S$. typhimurium encodes an activator of Rho GTPases that induces membrane ruffling and nuclear responses in host cells. Cell 93: 815826.

Hayes CS, Aoki SK, Low DA. 2010. Bacterial contact-dependent delivery systems. Annu Rev Genet 44: 71-90.

Henkel JS, Baldwin MR, Barbieri JT. 2010. Toxins from bacteria. EXS 100: $1-29$.

Henriksson ML, Sundin C, Jansson AL, Forsberg A, Palmer RH, Hallberg B. 2002. Exoenzyme $S$ shows selective ADP-ribosylation and GTPaseactivating protein (GAP) activities towards small GTPases in vivo. Biochem J 367: 617-628.

Hernandez LD, Hueffer K, Wenk MR, Galan JE. 2004. Salmonella modulates vesicular traffic by altering phosphoinositide metabolism. Science 304: 1805-1807.

Holt MR, Koffer A. 2001. Cell motility: Proline-rich proteins promote protrusions. Trends Cell Biol 11: 38-46.

Huang Z, Sutton SE, Wallenfang AJ, Orchard RC, Wu X, Feng Y, Chai J, Alto NM. 2009. Structural insights into host GTPase isoform selection by a family of bacterial GEF mimics. Nat Struct Mol Biol 16: 853-860.

Huibregtse JM, Scheffner M, Beaudenon S, Howley PM. 1995. A family of proteins structurally and functionally related to the E6-AP ubiquitinprotein ligase. Proc Natl Acad Sci 92: 2563-2567.

Iriarte M, Cornelis GR. 1998. YopT, a new Yersinia Yop effector protein, affects the cytoskeleton of host cells. Mol Microbiol 29: 915-929.

Ishido S, Wang C, Lee BS, Cohen GB, Jung JU. 2000. Downregulation of major histocompatibility complex class I molecules by Kaposi's sarcoma-associated herpesvirus K3 and K5 proteins. J Virol 74: 5300-5309.

Jiang P, Mayo AE, Ninfa AJ. 2007. Escherichia coli glutamine synthetase adenylyltransferase (ATase, EC 2.7.7.49): Kinetic characterization of regulation by PII, PII-UMP, glutamine, and $\alpha$-ketoglutarate. Biochemistry 46: 4133-4146.

Jubelin G, Taieb F, Duda DM, Hsu Y, Samba-Louaka A, Nobe R, Penary M, Watrin C, Nougayrede JP, Schulman BA, et al. 2010. Pathogenic bacteria target NEDD8-conjugated cullins to hijack host-cell signaling pathways. PLoS Pathog 6: e1001128.

Juris SJ, Rudolph AE, Huddler D, Orth K, Dixon JE. 2000. A distinctive role for the Yersinia protein kinase: Actin binding, kinase activation, and cytoskeleton disruption. Proc Natl Acad Sci 97: 9431-9436. 
Kenny B, DeVinney R, Stein M, Reinscheid DJ, Frey EA, Finlay BB. 1997. Enteropathogenic E. coli (EPEC) transfers its receptor for intimate adherence into mammalian cells. Cell 91: 511-520.

Kinch LN, Yarbrough ML, Orth K, Grishin NV. 2009. Fido, a novel AMPylation domain common to fic, doc, and AvrB. PLoS ONE 4: e5818.

Klink BU, Barden S, Heidler TV, Borchers C, Ladwein M, Stradal TE, Rottner K, Heinz DW. 2010. Structure of Shigella IpgB2 in complex with human RhoA: Implications for the mechanism of bacterial guanine nucleotide exchange factor mimicry. J Biol Chem 285: 1719717208.

Kubori T, Galan JE. 2003. Temporal regulation of Salmonella virulence effector function by proteasome-dependent protein degradation. Cell 115: 333-342.

Li H, Xu H, Zhou Y, Zhang J, Long C, Li S, Chen S, Zhou JM, Shao F. 2007. The phosphothreonine lyase activity of a bacterial type III effector family. Science 315: 1000-1003.

Liverman AD, Cheng HC, Trosky JE, Leung DW, Yarbrough ML, Burdette DL, Rosen MK, Orth K. 2007. Arp2/3-independent assembly of actin by Vibrio type III effector VopL. Proc Natl Acad Sci 104: 17117-17122.

Luong P, Kinch LN, Brautigam CA, Grishin NV, Tomchick DR, Orth K. 2010. Kinetic and structural insights into the mechanism of AMPylation by VopS Fic domain. J Biol Chem 285: 20155-20163.

Miraglia AG, Travaglione S, Meschini S, Falzano L, Matarrese P, Quaranta MG, Viora M, Fiorentini C, Fabbri A. 2007. Cytotoxic necrotizing factor 1 prevents apoptosis via the Akt/IкB kinase pathway: Role of nuclear factor- $\kappa \mathrm{B}$ and Bcl-2. Mol Biol Cell 18: 2735-2744.

Mittal R, Peak-Chew SY, McMahon HT. 2006. Acetylation of MEK2 and ІкB kinase (IKK) activation loop residues by YopJ inhibits signaling. Proc Natl Acad Sci 103: 18574-18579.

Mohr C, Koch G, Just I, Aktories K. 1992. ADP-ribosylation by Clostridium botulinum C3 exoenzyme increases steady-state GTPase activities of recombinant rhoA and rhoB proteins. FEBS Lett 297: 95-99.

Morikawa H, Kim M, Mimuro H, Punginelli C, Koyama T, Nagai S, Miyawaki A, Iwai K, Sasakawa C. 2010. The bacterial effector Cif interferes with SCF ubiquitin ligase function by inhibiting deneddylation of Cullin1. Biochem Biophys Res Commun 401: 268-274.

* Morrison D. 2012. MAP kinase pathways. Cold Spring Harb Perspect Biol doi: 10.1101/cshperspect.a011254.

Mukherjee S, Keitany G, Li Y, Wang Y, Ball HL, Goldsmith EJ, Orth K. 2006. Yersinia YopJ acetylates and inhibits kinase activation by blocking phosphorylation. Science 312: 1211-1214.

Mukherjee S, Hao YH, Orth K. 2007. A newly discovered post-translational modification-The acetylation of serine and threonine residues. Trends Biochem Sci 32: 210-216.

Mukherjee S, Liu X, Arasaki K, McDonough J, Galan JE, Roy CR. 2011. Modulation of Rab GTPase function by a protein phosphocholine transferase. Nature 477: 103-106.

Mukhopadhyay D, Riezman H. 2007. Proteasome-independent functions of ubiquitin in endocytosis and signaling. Science 315: 201-205.

Muller MP, Peters H, Blumer J, Blankenfeldt W, Goody RS, Itzen A. 2010. The Legionella effector protein DrrA AMPylates the membrane traffic regulator Rablb. Science 329: 946-949.

Murata T, Delprato A, Ingmundson A, Toomre DK, Lambright DG, Roy CR. 2006. The Legionella pneumophila effector protein DrrA is a Rab1 guanine nucleotide-exchange factor. Nat Cell Biol 8: 971-977.

Namgoong S, Boczkowska M, Glista MJ, Winkelman JD, Rebowski G, Kovar DR, Dominguez R. 2011. Mechanism of actin filament nucleation by Vibrio VopL and implications for tandem W domain nucleation. Nat Struct Mol Biol 18: 1060-1067.

Navarro L, Koller A, Nordfelth R, Wolf-Watz H, Taylor S, Dixon JE. 2007. Identification of a molecular target for the Yersinia protein kinase A. Mol Cell 26: 465-477.

Neunuebel MR, Chen Y, Gaspar AH, Backlund PSJr, Yergey A, Machner MP. 2011. De-AMPylation of the small GTPase Rab1 by the pathogen Legionella pneumophila. Science 333: 453-456.
* Newton K, Dixit V. 2012. Signaling in innate immunity and inflammation. Cold Spring Harb Perspect Biol doi: 10.1101/cshperspect.a006049.

Niebuhr K, Jouihri N, Allaoui A, Gounon P, Sansonetti PJ, Parsot C. 2000. IpgD, a protein secreted by the type III secretion machinery of Shigella flexneri, is chaperoned by IpgE and implicated in entry focus formation. Mol Microbiol 38: 8-19.

Niebuhr K, Giuriato S, Pedron T, Philpott DJ, Gaits F, Sable J, Sheetz MP, Parsot C, Sansonetti PJ, Payrastre B. 2002. Conversion of PtdIns(4,5)P(2) into PtdIns(5)P by the S. flexneri effector IpgD reorganizes host cell morphology. EMBO J 21: 5069-5078.

Norris FA, Wilson MP, Wallis TS, Galyov EE, Majerus PW. 1998. SopB, a protein required for virulence of Salmonella dublin, is an inositol phosphate phosphatase. Proc Natl Acad Sci 95: 14057-14059.

Offermanns S, Toombs CF, Hu YH, Simon MI. 1997. Defective platelet activation in $\mathrm{G} \alpha(\mathrm{q})$-deficient mice. Nature 389: 183-186.

Orth K, Palmer LE, Bao ZQ, Stewart S, Rudolph AE, Bliska JB, Dixon JE. 1999. Inhibition of the mitogen-activated protein kinase kinase superfamily by a Yersinia effector. Science 285: 1920-1923.

Orth K, Xu Z, Mudgett MB, Bao ZQ, Palmer LE, Bliska JB, Mangel WF, Staskawicz B, Dixon JE. 2000. Disruption of signaling by Yersinia effector YopJ, a ubiquitin-like protein protease. Science 290: 15941597.

Pickart CM. 2004. Back to the future with ubiquitin. Cell 116: 181-190.

Prehna G, Ivanov MI, Bliska JB, Stebbins CE. 2006. Yersinia virulence depends on mimicry of host Rho-family nucleotide dissociation inhibitors. Cell 126: 869-880.

Querido E, Blanchette P, Yan Q, Kamura T, Morrison M, Boivin D, Kaelin WG, Conaway RC, Conaway JW, Branton PE. 2001a. Degradation of p53 by adenovirus E4orf6 and E1B55K proteins occurs via a novel mechanism involving a Cullin-containing complex. Genes Dev 15: 3104-3117.

Querido E, Morrison MR, Chu-Pham-Dang H, Thirlwell SW, Boivin D, Branton PE. 2001b. Identification of three functions of the adenovirus e4orf6 protein that mediate p53 degradation by the E4orf6-E1B55K complex. J Virol 75: 699-709.

Randow F, Lehner PJ. 2009. Viral avoidance and exploitation of the ubiquitin system. Nat Cell Biol 11: 527-534.

Rigden DJ. 2011. Identification and modelling of a PPM protein phosphatase fold in the Legionella pneumophila deAMPylase SidD. FEBS Lett 585: 2749-2754.

Rohde JR, Breitkreutz A, Chenal A, Sansonetti PJ, Parsot C. 2007. Type III secretion effectors of the IpaH family are E3 ubiquitin ligases. Cell Host Microbe 1: 77-83.

Sallee NA, Rivera GM, Dueber JE, Vasilescu D, Mullins RD, Mayer BJ, Lim WA. 2008. The pathogen protein $\operatorname{EspF}(\mathrm{U})$ hijacks actin polymerization using mimicry and multivalency. Nature 454: 1005-1008.

* Sassone-Corsi P. 2012. The cyclic AMP pathway. Cold Spring Harb Perspect Biol doi: 10.1101/cshperspect.a011148.

Scheffner M, Huibregtse JM, Vierstra RD, Howley PM. 1993. The HPV16 E6 and E6-AP complex functions as a ubiquitin-protein ligase in the ubiquitination of p53. Cell 75: 495-505.

Schmidt G, Sehr P, Wilm M, Selzer J, Mann M, Aktories K. 1997. Gln 63 of Rho is deamidated by Escherichia coli cytotoxic necrotizing factor-1. Nature 387: 725-729.

Sehr P, Joseph G, Genth H, Just I, Pick E, Aktories K. 1998. Glucosylation and ADP ribosylation of rho proteins: Effects on nucleotide binding, GTPase activity, and effector coupling. Biochemistry 37: 5296-5304.

Selyunin AS, Sutton SE, Weigele BA, Reddick LE, Orchard RC, Bresson SM, Tomchick DR, Alto NM. 2011. The assembly of a GTPase-kinase signalling complex by a bacterial catalytic scaffold. Nature 469: 107111.

Shao F, Merritt PM, Bao Z, Innes RW, Dixon JE. 2002. A Yersinia effector and a Pseudomonas avirulence protein define a family of cysteine proteases functioning in bacterial pathogenesis. Cell 109: 575-588.

Shao F, Vacratsis PO, Bao Z, Bowers KE, Fierke CA, Dixon JE. 2003. Biochemical characterization of the Yersinia YopT protease: Cleavage 
N.M. Alto and K. Orth

site and recognition elements in Rho GTPases. Proc Natl Acad Sci 100: 904-909.

Singer AU, Rohde JR, Lam R, Skarina T, Kagan O, Dileo R, Chirgadze NY, Cuff ME, Joachimiak A, Tyers M, et al. 2008. Structure of the Shigella T3SS effector IpaH defines a new class of E3 ubiquitin ligases. Nat Struct Mol Biol 15: 1293-1301.

* Staudt LM. 2012. TLR/NF-кB pathway. Cold Spring Harb Perspect Biol doi: $10.1101 /$ cshperspect.a011247.

Stebbins CE, Galan JE. 2000. Modulation of host signaling by a bacterial mimic: Structure of the Salmonella effector SptP bound to Rac1. Mol Cell 6: $1449-1460$.

Stevenson PG, Efstathiou S, Doherty PC, Lehner PJ. 2000. Inhibition of MHC class I-restricted antigen presentation by $\gamma 2$-herpesviruses. Proc Natl Acad Sci 97: 8455-8460.

Takai Y, Sasaki T, Matozaki T. 2001. Small GTP-binding proteins. Physiol Rev 81: 153-208.

Tan Y, Luo ZQ. 2011. Legionella pneumophila SidD is a deAMPylase that modifies Rab1. Nature 475: 506-509.

Terebiznik MR, Vieira OV, Marcus SL, Slade A, Yip CM, Trimble WS, Meyer T, Finlay BB, Grinstein S. 2002. Elimination of host cell PtdIns $(4,5) \mathrm{P}(2)$ by bacterial SigD promotes membrane fission during invasion by Salmonella. Nat Cell Biol 4: 766-773.

Trosky JE, Mukherjee S, Burdette DL, Roberts M, McCarter L, Siegel RM, Orth K. 2004. Inhibition of MAPK signaling pathways by VopA from Vibrio parahaemolyticus. J Biol Chem 279: 51953-51957.

Trosky JE, Li Y, Mukherjee S, Keitany G, Ball H, Orth K. 2007. VopA inhibits ATP binding by acetylating the catalytic loop of MAPK kinases. J Biol Chem 282: 34299-34305.

Upadhyay A, Wu HL, Williams C, Field T, Galyov EE, van den Elsen JM, Bagby S. 2008. The guanine-nucleotide-exchange factor BopE from Burkholderia pseudomallei adopts a compact version of the Salmonella SopE/SopE2 fold and undergoes a closed-to-open conformational change upon interaction with Cdc42. Biochem J 411: 485-493.

Von Pawel-Rammingen U, Telepnev MV, Schmidt G, Aktories K, WolfWatz H, Rosqvist R. 2000. GAP activity of the Yersinia YopE cytotoxin specifically targets the Rho pathway: A mechanism for disruption of actin microfilament structure. Mol Microbiol 36: 737-748.

Welch MD, Rosenblatt J, Skoble J, Portnoy DA, Mitchison TJ. 1998. Interaction of human Arp2/3 complex and the Listeria monocytogenes ActA protein in actin filament nucleation. Science 281: 105-108.

Woolery AR, Luong P, Broberg CA, Orth K. 2010. AMPylation: Something old is new again. Front Microbiol 1: 113.

Worby CA, Mattoo S, Kruger RP, Corbeil LB, Koller A, Mendez JC, Zekarias B, Lazar C, Dixon JE. 2009. The Fic domain: Regulation of cell signaling by adenylylation. Mol Cell 34: 93-103.

* Yaffe MB. 2012. Protein regulation. Cold Spring Harb Perspect Biol doi: 10.1101/cshperspect.a005918.

Yarbrough ML, Li Y, Kinch LN, Grishin NV, Ball HL, Orth K. 2009. AMPylation of Rho GTPases by Vibrio VopS disrupts effector binding and downstream signaling. Science 323: 269-272.

Yu Y, Wang SE, Hayward GS. 2005. The KSHV immediate-early transcription factor RTA encodes ubiquitin E3 ligase activity that targets IRF7 for proteosome-mediated degradation. Immunity 22: 59-70.

Yu B, Cheng HC, Brautigam CA, Tomchick DR, Rosen MK. 2011. Mechanism of actin filament nucleation by the bacterial effector VopL. Nat Struct Mol Biol 18: 1068-1074.

Zhu Y, Li H, Hu L, Wang J, Zhou Y, Pang Z, Liu L, Shao F. 2008. Structure of a Shigella effector reveals a new class of ubiquitin ligases. Nat Struct Mol Biol 15: 1302-1308. 


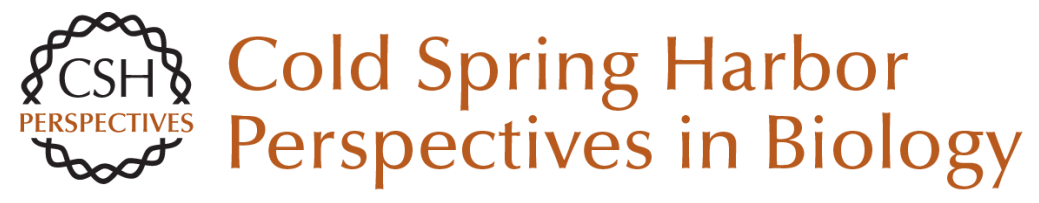

\section{Subversion of Cell Signaling by Pathogens}

Neal M. Alto and Kim Orth

Cold Spring Harb Perspect Biol 2012; doi: 10.1101/cshperspect.a006114

Subject Collection Signal Transduction

Cell Signaling and Stress Responses Gökhan S. Hotamisligil and Roger J. Davis

Protein Regulation in Signal Transduction Michael J. Lee and Michael B. Yaffe

Synaptic Signaling in Learning and Memory Mary B. Kennedy

Vertebrate Reproduction Sally Kornbluth and Rafael Fissore

Signaling in Lymphocyte Activation Doreen Cantrell

Signaling in Muscle Contraction Ivana Y. Kuo and Barbara E. Ehrlich

Toll-Like Receptor Signaling Kian-Huat Lim and Louis M. Staudt

Signaling Pathways that Regulate Cell Division Nicholas Rhind and Paul Russell
Second Messengers

Alexandra C. Newton, Martin D. Bootman and John D. Scott

Signals and Receptors Carl-Henrik Heldin, Benson Lu, Ron Evans, et al.

Cell Death Signaling Douglas R. Green and Fabien Llambi

Signaling Networks that Regulate Cell Migration Peter Devreotes and Alan Rick Horwitz

Signaling Networks: Information Flow, Computation, and Decision Making Evren U. Azeloglu and Ravi lyengar

Signal Transduction: From the Atomic Age to the Post-Genomic Era Jeremy Thorner, Tony Hunter, Lewis C. Cantley, et al.

Signaling by the TGF $\beta$ Superfamily Jeffrey L. Wrana

Subversion of Cell Signaling by Pathogens Neal M. Alto and Kim Orth

For additional articles in this collection, see http://cshperspectives.cshlp.org/cgi/collection/

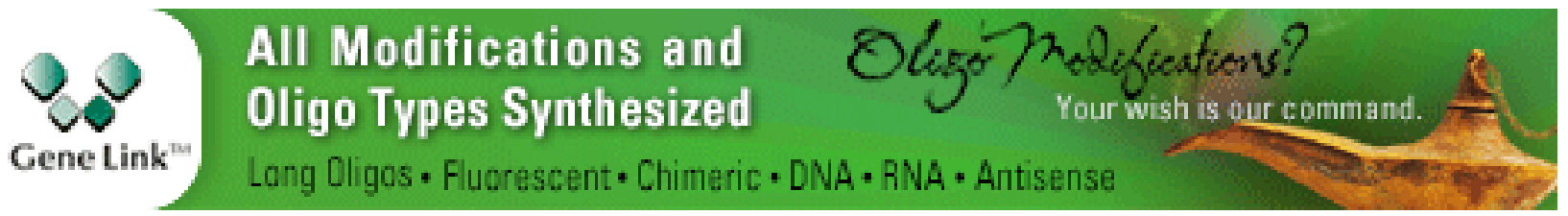

Copyright @ 2012 Cold Spring Harbor Laboratory Press; all rights reserved 